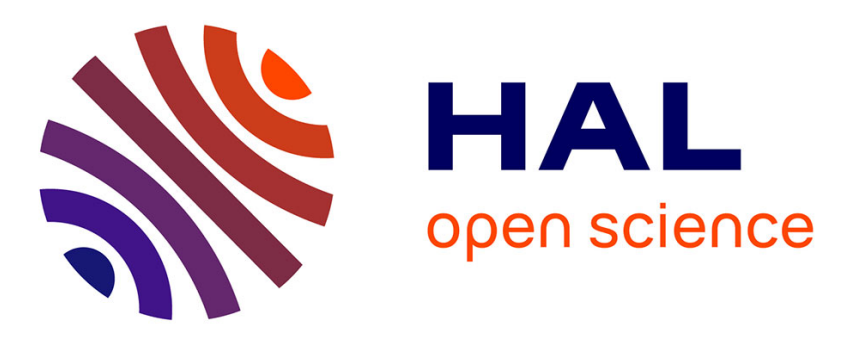

\title{
In search of artificial domatia for predatory mites
}

Cecile Bresch, Lea Carlesso, Ricardo Suay, Louise van Oudenhove, Suzanne Touzeau, Hicham Fatnassi, Lydia Ottenwaelder, B. Paris, Christine Poncet, Ludovic Mailleret, et al.

\section{- To cite this version:}

Cecile Bresch, Lea Carlesso, Ricardo Suay, Louise van Oudenhove, Suzanne Touzeau, et al.. In search of artificial domatia for predatory mites. Biocontrol Science and Technology, 2019, 29 (2), pp.1-18. 10.1080/09583157.2018.1540030 . hal-01947693

\section{HAL Id: hal-01947693 https://hal.inria.fr/hal-01947693}

Submitted on 7 Jan 2020

HAL is a multi-disciplinary open access archive for the deposit and dissemination of scientific research documents, whether they are published or not. The documents may come from teaching and research institutions in France or abroad, or from public or private research centers.
L'archive ouverte pluridisciplinaire HAL, est destinée au dépôt et à la diffusion de documents scientifiques de niveau recherche, publiés ou non, émanant des établissements d'enseignement et de recherche français ou étrangers, des laboratoires publics ou privés. 


\section{In search of artificial domatia for predatory mites}

2 Bresch C. ${ }^{\mathrm{a}}$, Carlesso L. ${ }^{\mathrm{a}, \mathrm{b}}$, Suay R. ${ }^{\mathrm{a}}$, Van Oudenhove L. ${ }^{\mathrm{a}}$, Touzeau S. ${ }^{\mathrm{a}, \mathrm{c}}$,

3 Fatnassi H. ${ }^{a}$, Ottenwaelder L. ${ }^{a}$, Paris B. ${ }^{a, d}$, Poncet C. ${ }^{a}$, Mailleret L. ${ }^{a, c}$,

4 Messelink G.J. ${ }^{\mathrm{e}}$, Parolin P. ${ }^{\mathrm{a}, \mathrm{f}}$

5 a'Université Côte d'Azur, INRA, CNRS, ISA, France

$6 \quad{ }^{b}$ Rothamsted Research, Department of Sustainable Soils and Grassland Systems, West

7 Common, Harpenden, Hertfordshire AL5 2JQ,United Kingdom

8 'Université Côte d'Azur, Inria, INRA, CNRS, UPMC Univ Paris 06, BIOCORE, France

$9 \quad{ }^{\mathrm{d}}$ Astredhor, 44 rue d'Alésia 75682 Paris cedex 14

$10{ }^{e}$ Wageningen UR Greenhouse Horticulture; PO Box 20, 2265 ZG Bleiswijk, The

11 Netherlands

$12{ }^{\dagger}$ Humboldt-Universität zu Berlin, Faculty of Life Sciences, Division Urban Plant

13 Ecophysiology, Lentzelallee 55-57, 14195 Berlin, Germany

14

15 Léa Carlesso

16 https://orcid.org/0000-0002-6527-4112

17 Ricardo Suay

18 https://orcid.org/0000-0003-1604-8132

19 Louise Van Oudenhove

20 https://orcid.org/0000-0001-5251-7464 
21 Suzanne Touzeau

22 https://orcid.org/0000-0001-5255-8960

23 Hicham Fatnassi

24 https://orcid.org/0000-0002-9729-0504

25 Christine Poncet

26 https://orcid.org/0000-0001-5800-5996

27 Ludovic Mailleret

28 https://orcid.org/0000-0001-7019-8401

29 Gerben Messelink

30 https://orcid.org/0000-0002-5196-1229

31 Pia Parolin

32 https://orcid.org/0000-0003-3947-7132

33

34 Corresponding author: Cécile Bresch

35 https://orcid.org/0000-0003-4056-0531

36 E-mail address: cecile.bresch@inra.fr

37

38 Manuscript word count: 7370 words 


\section{Abstract}

Banker plants can enhance biological pest control by providing both floral resources and appropriate oviposition sites, e.g. through acarodomatia, to predator species. The use of materials mimicking domatia i.e., artificial domatia may be an economically favourable alternative to the use of banker plants bearing domatia. The aim of the present study was to identify materials that are able to host eggs of the Neoseiulus californicus predatory mite but not those of the Tetranychus urticae pest mite. In a laboratory experiment, the oviposition of predatory and phytophagous mites were compared in Petri dishes containing leaves. The different modalities compared were (i) natural domatia of Viburnum tinus or (ii) one of twelve potential artificial domatia materials. The overall oviposition response of predatory mites to all artificial domatia was similar to that of the natural domatia. The oviposition of the Tetranychus urticae pest mite did not increase in response to the artificial domatia. Five artificial domatia hosted as many eggs of the predatory mite as observed in the natural domatia. The effect of the physical properties of artificial domatia was also tested and $N$. californicus was found to favour the artificial domatia that had high heat retention capacities for oviposition. Three of these artificial domatia were tested on rose plants in a greenhouse experiment; none of which enhanced the biological control on the plants under these conditions. The present study highlights the difficulty in identifying and using suitable artificial domatia as substitutes to banker plants in biological pest control efforts.

Keywords: Neoseiulus californicus; Tetranychus urticae; banker plant; domatia; microhabitat; biological pest control.

\section{Introduction}

In integrated pest management, natural enemies such as predatory mites are frequently used to control pests on crops (Gerson \& Weintraub, 2012). Neoseiulus californicus (MacGregor), (Acari: Phytoseiidae) also known as N. chilenensis Dosse is a predatory 
69 mite that may potentially be used in the biocontrol of the two-spotted spider mite

70 Tetranychus urticae Koch (Easterbrook, M. A., Fitzgerald, J. D., \& Solomon, M. G.,

71 2001; García-Marí \& González-Zamora, 1999). However, low establishment rates and

72 the persistence of natural enemies are sometimes observed in various cropping systems

73 (Messelink et al., 2014). Indeed, in order for a population to become established in a

74 crop without prey or with low prey density, predatory mites need alternative or

75 supplementary food sources, such as pollen or nectar (Kumar et al., 2014; McMurtry \&

76 Croft, 1997) and oviposition and shelter sites with trichomes or domatia (Kreiter, S.,

77 Tixier, M. S., Croft, B. A., Auger, P., \& Barret, D., 2002; Walter D. E. \& O'Dowd J.R., 78 1996).

79 Acarodomatia are tufts of hair or invaginations under the leaf surface (English-

80 English-Loeb, G.; Andrew, P. N. \& Walker, M. A., 2002) usually on the main vein axils

81 (Adar, E., Inbar, M., Gal, S., Gan-Mor, S., \& Palevsky, E., 2014). Parolin, P., Bresch,

82 C., Van Oudenhove, L., Errard, \& A., Poncet, C. (2013) demonstrated that $N$.

83 californicus prefer to lay eggs on plants bearing domatia. They have been shown to

84 influence the distribution, to increase the abundance and to improve the reproduction of

85 predatory mites (Agrawal, A. A., Karban, R., \& Colfer, R.G., 2000; Grostal \& O'Dowd,

86 1994; Norton, A. P., English-Loeb, G., \& Belden, E., 2001; Pemberton \& Turner, 1989;

87 Walter, 1996; Walter \& O’Dowd, 1992). Furthermore, domatia offer mites protection

88 from predators (Faraji, F., Janssen, A., \& Sabelis, M. W., 2002; Norton et al., 2001;

89 Roda, A., Nyrop, J., Dicke, M., \& English-Loeb,G., 2000). Domatia presumably also

90 buffer the effects of changes in relative air humidity (RH) (Grostal \& O’Dowd, 1994;

91 O’Dowd \& Willson, 1989), however, the microclimate benefits of domatia on mite

92 populations has not yet been clarified (Ferreira, J. A. M., Pallini, A., Oliveira, C. L.,

93 Sabelis, M. W., \& Janssen, A., 2010; Norton et al., 2001). 
As many crops cannot provide both floral resources and oviposition sites at all stages of their development, it is challenging to maintain predatory mite populations on crops when prey are scarce (Adar et al., 2014; Messelink et al., 2014). The use of banker plants that provide oviposition sites and floral resources is one option to overcome these problems. Banker plants form 'a rearing and release system [that is] purposefully added to or established in a crop for pest control in greenhouses or open fields’ (Huang et al., 2011) and they may influence the establishment and reproduction of released natural enemies (Frank, 2010; Huang et al., 2011; Parolin et al., 2013). Crops such as rose plants are not suitable for predatory mite oviposition as they do not bear domatia. Moreover, when rose stems are regularly harvested, a part of the predatory mite population is removed from the greenhouse and this harvest may consequently have a significant impact on pest suppression (Nundloll, S.; Mailleret, L. \& Grognard, F., 2008). In a greenhouse study, a rose crop was much less damaged by the T. urticae pest when Viburnum tinus L. (Adoxaceae), a plant bearing acarodomatia, was present as a banker plant (Parolin et al., 2013). The presence of $V$. tinus resulted in increased numbers of $N$. californicus as well as a decreased population of T. urticae. Another greenhouse study showed improved spider mite control by predatory mites when plants containing many domatia (V. tinus L. and Vitis riparia Michx, Vitaceae) were included amongst the rose plants (Parolin et al., 2015).

In the literature, various studies have reported the potential of plants with acarodomatia to develop a significant and sustainable population of predatory mites, inducing the decline of phytophagous mites and increasing crop health without pesticide applications (Grostal \& O’Dowd, 1994; Karban, R., English-Loeb, G., Walker, M.A., \& Thaler, J., 1995; Parolin et al., 2013; Walter \& O’Dowd, 1992). Nevertheless, the use of secondary plants that provide acarodomatia can be time-consuming and costly due to 
119 the additional time needed for maintenance and pruning. The use of banker plants also

120 reduces the space available for the crops. These issues hamper the utilization of banker

121 plants by commercial plant producers.

Various studies have tried to mimic trichomes and to create artificial domatia on crops. For example, Rozario (1994) observed higher reproductive outputs of the predator Galendromus occidentalis Nesbitt (Acari: Phytoseiidae) when tufts of polyester fibres were added to the vein axils of grape varieties with low natural domatia density. Loughner, R., Wentworth, K., Loeb, G., \& Nyrop, J. (2010) found that increased habitat complexity on leaves, e.g. trichome density mimicked with cotton fibre patches, reduced adult dispersal of Typhlodromus pyri Scheuten (Acari: Phytoseiidae) from plants. Roda et al. (2001) tested the effect of the leaf surface topography on phytoseiid behaviour. T. pyri and Phytoseiulus persimilis Athias-Henriot (Acari: Phytoseiidae) were shown to spend more time and oviposit more frequently on leaf surfaces with cotton fibres compared to surfaces without these microstructures. Loughner, R., Nyrop, J., Wentworth, K., \& Sanderson, J., (2011) showed that the application of both chopped acrylic fibres and pollen on the canopy of plants improved the persistence and egg production of Amblyseius swirskii (Athias-Henriot). In a laboratory trial, Kawashima, M., Adachi, I., \& Toyama, M. (2006) tested the colonization efficiency of 22 types of artificial microstructures by $N$. californicus adults. Textured urethane foam and polyethylene shading nets were preferentially colonized by adult predatory mites. Kawashima, M., \& Jung, C. (2011) studied the effects of sheltered ground habitat on $N$. californicus populations in apple orchards and concluded that the presence of urethane foam deposited on the ground may potentially improve the survival of the predatory mite in winter. These findings are consistent with those of Zhao et al. (2014) who demonstrated that natural ground cover had a positive effect on the biological control of 
144 Panonychus citri McGregor (Acari: Tetranychidae). Adar et al. (2014) tested a solution

145 including pollen application, shelter and oviposition sites for predatory mites by

146 installing pollen coated twines on pepper plants. The combination of an artificial pollen

147 reservoir and oviposition and shelter sites increased the populations of $A$. swirskii and

148 Euseius scutalis (Athias-Henriot) (Acari: Phytoseiidae). Pekas and Wäckers (2017)

149 tested the impact of single and combined resources (fibres, pollen, and sugar) on the

150

151

152

153

154

155

156

157

158

159

160

161

162

163

164

165

166

167 oviposition of Euseius stipulatus (Athias-Henriot) (Acari: Phytoseiidae) on Citrus aurantium L. (Rutaceae), and showed that the impact of the fibres was significant when combined with pollen. The combination of the three resources resulted in the highest oviposition of the predatory mite. All these studies tend to show that artificial domatia, in particular when combined with a food resource (mostly pollen), favour the development of predatory mites.

The main objective of this study was to identify materials that provide suitable oviposition sites, i.e. artificial domatia, for the N. californicus predatory mite in a mild climate area in Southern France. To achieve this goal, we conducted laboratory and greenhouse experiments with various materials. Based on the literature, we not only provided predatory mites with materials, but also with food resources to favour their development.

More specifically, the following questions were addressed:

(1) Do materials act as artificial domatia and promote an overall oviposition of the predatory mite similar to natural domatia in laboratory conditions? If so, which materials are most suitable?

(2) Do these materials also increase the number of pest mites in the same laboratory conditions? 
(3) Under greenhouse conditions, does the presence of artificial domatia on rose

169

170

171

172

173 plants enhance the biological control of the pest mite by the predatory mite. If so, which types of artificial domatia are most effective?

\section{Materials and methods}

We selected twelve different materials and assessed the oviposition of N. californicus predatory mites and $T$. urticae pest mites on the different materials in experimental units containing both predator and pest individuals, as well as the natural or artificial domatia in laboratory experiments. Three of these materials were subsequently tested on rose plants in a greenhouse experiment. The experiments were conducted in spring 2014 in a laboratory setting and in summer 2015 in a greenhouse at the French National Institute for Agricultural Research (INRA) Sophia Antipolis site in Southern France (43³6'44.9" N latitude, 0704'40.4" E longitude, 125 m altitude).

\section{Selection of artificial domatia}

Materials were selected based on (i) characteristics that were similar to acarodomatia, such as density, thickness, fibre diameter, and morphology; and (ii) structural differences from natural domatia. We also considered that ideal materials should be affordable; easy to remove; long-lasting; resistant to water, solar radiation and fungi; and be easy to handle and maintain.

We assessed the structural characteristics (density, thickness, fibre diameter, morphology) and trichome size of $V$. tinus acarodomatia using a binocular magnifier (Fig. 1a). We then screened commercial and suitable materials to find those with similar characteristics, with a preference for woven fibres instead of finely-chopped fibres for easier manipulation, installation and removability from a crop system. In addition, we 
191 looked for materials that offered different characteristics related to RH absorbency, heat

192 retention, morphology, thickness, fibre density and fibre diameter. These criteria led to

193 the selection of twelve artificial materials that were purchased from the TOTO TISSUS

194 outlet in Cannes, France: acrylic, acetate, linen, silk, viscose, wool and two types of

195 polyamide, polyester and cotton (Table 1).

196 RH absorbency ability can be defined as the capacity of fibres to reach moisture 197 balance. The heat retention capacity of fibres refers to their thermal-retaining properties 198 (Ishimaru, 2016). RH absorbency and heat retention capacities were obtained from the

199 literature (see Table 1). Materials were distinguished according to two types of

200 morphology: tightly woven fibres and more loosely woven fibres (Fig. 1b, 1c), with the 201 latter being more similar to acarodomatia (Fig. 1a). Thickness and fibre diameter were

213 - INSERT Table 1 -

215 - INSERT Figure 1-a.b.c - 


\section{Laboratory experiment}

218 The plant species used in the experiment were Rosa Emera ${ }^{\circledR}$, Decorosier ${ }^{\circledR}$ and $V$. tinus

219 grown at INRA Sophia Antipolis, which were pest and pesticide free. The T. urticae pest

220 mites used as prey for predatory mites were reared on bean plants in growth chambers

221 ( $23{ }^{\circ} \mathrm{C}, 70 \% \mathrm{RH}, 16-8 \mathrm{~h} \mathrm{D} / \mathrm{N}$ photoperiod). The Spical ${ }^{\circledR}$ commercial strain of $N$.

222 californicus predatory mites (KOPPERT, B.V. The Netherlands) was released onto the 223 experimental arenas within two days of their delivery. The sex ratio of $N$. californicus

224 was 3:2 females:males (KOPPERT). Both mite species showed a range of instars.

225

226

Typha angustifolia L. pollen (Nutrimite ${ }^{\mathrm{TM}}$, BIOBEST Group, Westerlo, Belgium) was supplied ad libitum as alternative food for the predator population (Marafeli et al., 2014).

Experimental units were $14 \mathrm{~cm}$ diameter Petri dishes containing both the predator and the pest, as well as the natural or artificial domatia, pollen and leaves (Fig. 2a). On day 1, moistened filter paper and a $12 \mathrm{~cm}$ long rose plant leaf (on top of the filter paper) were placed in each Petri dish. In addition, either a $4 \mathrm{~mm}^{2}$ piece of one type of artificial domatia or a $7 \mathrm{~cm} V$. tinus leaf providing $4 \mathrm{~mm}^{2}$ natural domatia was introduced in the experimental unit. The $4 \mathrm{~mm}^{2}$ area of natural domatia was determined from photographs using ImageJ software. On day 2, each experimental unit was inoculated with bean leaves infested with T. urticae. Each Petri dish received 140 units of prey (Castagnoli, M.; Simoni, S. \& Nachman, Gö, 2001); a unit of prey was defined as either one nymph or two eggs of T. urticae. On day 3, $40 \mathrm{~N}$. californicus adults and $100 \mathrm{mg}$ of pollen were added to each Petri dish. Pollen was placed next to the filter paper to avoid influencing the oviposition inside artificial or natural domatia. Petri 
240 dishes were sealed with Parafilm and randomly placed on tables in a laboratory. The

241 experiment included ten repetitions for each modality, artificial and natural domatia,

242 which resulted in a total of 130 Petri dishes.

- INSERT Figure 2-a.b -

The laboratory was maintained under controlled climatic conditions with a $16 \mathrm{~h}$

247

248

\section{Greenhouse experiment}

The experiment was performed in two compartments of a glass greenhouse. The biological control effect of the three artificial domatia was tested on rose plants. As described for the laboratory experiment, the same Spical ${ }^{\circledR}$ commercial strain and the alternative food Nutrimite ${ }^{\mathrm{TM}}$ were used. The rose plants Rosa rekord 'Pink Emely' ${ }^{\circledR}=$ Rosa kordes ${ }^{\circledR}$ 'Korselary' were planted in 1.3 L pots filled with Agrilit 3® perlite and Humomot compost, in a 1:2 ratio, at $6.5 \mathrm{pH}$ and with $1.08 \mathrm{mS} / \mathrm{cm}$ electrical conductivity (EC). Before the beginning of the experiment, the rose plants were 
acclimated in the greenhouse for one week at $21^{\circ} \mathrm{C}\left( \pm 3.9^{\circ} \mathrm{C}\right.$ SD) and $66 \% \mathrm{RH}( \pm 13$ $\%$ SD). Planted pots were placed in a balanced design on tables in the greenhouse, without touching each other. A strip of polyamide, wool, or organic wool $(16.0 \times 0.5$ $\mathrm{cm})$ was installed on each rose plant in direct contact with the leaves from the top to the bottom of the rose plants (Fig. 2b). Plants without strips were also included as controls. The experiment included 16 repetitions for each treatment except for polyamide (i.e. 15 repetitions).

To prevent mite dispersal between plants, each pot was placed on a Petri dish in a tray filled with water reaching up to $5 \mathrm{~mm}$ below the base of the $10 \mathrm{~cm}$ diameter pots. The mean temperature of the greenhouse was $24{ }^{\circ} \mathrm{C}\left( \pm 3.7^{\circ} \mathrm{C}\right.$ SD) and mean $\mathrm{RH}$ was $72 \%$ ( $\pm 12 \% \mathrm{SD})$ throughout the experiment.

On day 1 , each rose plant was inoculated with adults $(\mathrm{n}=10)$ and nymphs $(\mathrm{n}=$ 10) of the T. urticae pest mite using a thin brush. On day 6, each plant was inoculated with $N$. californicus adults $(\mathrm{n}=10)$.

On day 33, eggs, nymphs and adults of both mite species were counted under the stereomicroscope (magnifying power $\times 20$ ) and their locations were recorded. In this study, “on” refers to the location being on and under the leaves of the rose plant and "inside" refers to the location being on and under the artificial domatia strip.

\section{Statistical analyses}

All analyses were conducted using R software (R Core Team 2014).

\section{Laboratory experiment}

We used the following 3-step analysis: 
(i) The effect of the artificial domatia was determined based on the total

oviposition by $N$. californicus. The response variable was the total number of eggs, laid both inside + outside, and the factor was the treatment, with levels corresponding to the twelve artificial domatia and natural domatia. A quasiPoisson generalized linear model (GLM) was used for the $N$. californicus analyses and a non-parametric Kruskal-Wallis test was used for the $T$. urticae analyses. The latter test was chosen because parametric models did not provide adequate fits.

A Wilcoxon signed rank test was conducted to determine whether $N$. californicus preferred to lay eggs inside or outside. For this test, we calculated the density of eggs by dividing the number of eggs laid inside by $0.04 \mathrm{~cm}^{2}$, i.e. the natural or artificial domatia area, and the number of eggs laid outside by $402.93 \mathrm{~cm}^{2}$, which is the area of the Petri dish and the leaves minus the natural/artificial domatia.

(ii) Comparisons were then made between the number of eggs laid inside the artificial and natural domatia using a negative binomial generalized linear model for $N$. californicus. Two treatments (i.e. cotton 2, polyamide 2) yielded no eggs inside and were, therefore, removed from the analyses. The natural domatia was used as the reference level for the treatment factor.

(iii) The effect of the physical properties of artificial domatia on the number of $N$. californicus eggs laid inside the artificial domatia was tested on the remaining artificial domatia. Properties that had no significant relationship (Pearson's correlation) with the number of eggs laid inside were excluded. Generalized linear models could not be fit to the data, due to the number of 
factors and zeros values, therefore, Hurdle negative binomial models were used. Different models that combined the remaining factors with and without

\section{Greenhouse experiment}

The effect of the artificial domatia strips was tested on the populations of predatory and

\section{Results}

\section{Laboratory experiment}

No significant difference in the total number of eggs (inside + outside) laid by $N$. californicus was observed among the artificial and natural domatia in the experimental

330 units (GLM: df = 12, p = 0.59; Fig. 3a). A mean of 13 eggs per replicate was laid by $N$. 331 californicus ( $\pm 13 \mathrm{SD})$. 
333 - INSERT Figure 3-a.b -

Neoseiulus californicus showed an oviposition preference inside natural domatia

336 rather than outside $(V=55, \mathrm{p}<0.001)$. A mean of $3.6( \pm 2.7 \mathrm{SD})$ eggs per Petri dish

337 was laid inside natural domatia. Neoseiulus californicus egg density was 100 times

338 higher inside natural domatia than outside. This level was similar for wool, viscose, silk,

339 polyamide 1 and polyester 2 (Table 2, Fig. 4). The remaining artificial domatia, i.e.

340 acetate, acrylic, cotton 1 , linen and polyester 1 , hosted significantly fewer eggs than the

341 natural domatia (Table 2, Fig. 4).

342

343 - INSERT Figure 4 -

344

345 - INSERT Table 2 -

346

348 No significant difference in the total number of eggs (inside + outside) laid by T. urticae

349 was observed between the artificial and natural domatia of $V$. tinus (Kruskal-Wallis test: $\chi^{2}(12)=18.76, p=0.09 ;$ Fig. 3b)

No eggs were laid by T. urticae inside the natural or the artificial domatia, and thus no further analyses were conducted. Pest mites only oviposited outside the artificial and natural domatia.

355 No significant correlations were found between the number of eggs laid by $N$. 
californicus inside the artificial domatia and the three physical properties of the artificial domatia: fibre density (correlation coefficient $r=-0.10, p=0.33$ ), fibre diameter $(r=$ $0.07, \mathrm{p}=0.47)$ and thickness $(\mathrm{r}=0.05, \mathrm{p}=0.64)$.

These three factors were excluded from the analysis and Hurdle models were built based on the three remaining factors, i.e. RH absorbency, morphology and heat retention. Different models that combined the remaining factors with and without their two-way interactions were tested.

The Hurdle model using the heat retention factor produced the lowest AIC (AIC = 268.5196). There were two other Hurdle models with slightly higher AIC. Both included the heat retention factor and either RH or breath, so we chose the simplest model with the heat retention factor only.The oviposition probability of $N$. californicus was significantly higher inside artificial domatia with a high heat retention capacity (Zero model: $\mathrm{p}=7.88 \mathrm{e}-05$ ).

According to these findings, the most favourable artificial domatia in terms of oviposition probability had high heat retention.

\section{Greenhouse experiment}

The mean total population of eggs, nymphs and adults per rose plant was: 12 ( $\pm 23 \mathrm{SD}$ ) $N$. californicus and 15 ( \pm 63 SD) T. urticae. The oviposition mean inside polyamide was 0.53 (SD 0.50) for N. californicus and 0.47 (SD 0.62) for T.urticae.

Fitting the data to the negative binomial generalized linear model raised the following issues: residuals were not acceptable for $N$. californicus and the model did not converge for T. urticae. Two outliers (two replicates) that could have been due to inoculation errors were removed: one was for the polyamide treatment ( $\mathrm{n}=50 \mathrm{~N}$. californicus, $\mathrm{n}=326$ T. urticae) and one for organic wool treatment ( $\mathrm{n}=10 \mathrm{~N}$. 
380

381

382

383

384

385

386

387

388

389

390

391

392

393

394

395

396

397

398

399

400

401

402

403

californicus, $\mathrm{n}=382$ T. urticae). Data excluding these replicates were used for subsequent analyses.

Without outliers, the mean total population was, per rose plant, 11 ( $\pm 23 \mathrm{SD}$ ) individuals for $N$. californicus (Fig. 5a) and 4 ( \pm 7 SD) individuals forT. urticae (Fig. $5 b)$.

The analysis for $N$. californicus data showed that neither the treatment nor the compartment factor had a significant effect on the population. The treatment factor was the only factor that had a significant effect on the $T$. urticae population $(\mathrm{df}=3$, residual deviation $=57.85, \mathrm{p}=0.02$; Fig. 5b).

- INSERT Figure 5-a.b -

The pest mite population per plant was significantly higher for the polyamide treatment than for the wool or the control treatment (respectively df $=1, \mathrm{Z}=-2.49, \mathrm{p}=$ $0.01 ; \mathrm{df}=1, \mathrm{Z}=-2.79, \mathrm{p}=0.005)$. The pest population on the plants was composed of $41 \%$ eggs and 59\% mobile stages for the polyamide treatment, which compares with the $48 \%$ eggs and $52 \%$ mobile stages for all treatments.

In conclusion, no artificial domatia strip increased the predator mite population in this greenhouse experiment. In contrast, an undesired side effect was observed, i.e. polyamide promoted an increase in the pest mite population.

\section{Discussion}

In the laboratory experiment, the total oviposition of $N$. californicus, i.e. inside + outside, was the same on all artificial domatia as was on the natural domatia. However, $N$. californicus clearly preferred to oviposit inside the natural domatia and five artificial 
domatia (wool, silk, polyamide, viscose and polyester). This preference occurred in spite of favourable environmental factors outside the artificial and natural domatia, i.e. absence of predators, high temperature and high RH. By providing mites with a narrow physical place to be in close contact (Gerson \& Weintraub, 2012), the artificial domatia appeared to favour the thigmotaxis behaviour of the predatory mites. Among the five artificial domatia found to be as attractive as natural domatia in this study, two of the same materials had also previously been tested, i.e. wool by Kawashima et al. (2006) and viscose (rayon) by Adar et al. (2014).

Kawashima et al. (2006) found the highest number of $N$. californicus adults inside wool in a choice test among eight artificial microstructures in a laboratory setting. Adar et al. (2014) observed that a twine made of rayon (80\%) and jute fibres (20\%) had a positive effect on A. swirskii and E. scutalis populations, with the majority of predatory mite eggs laid on the thin rayon fibres rather than on the thick jute.

No T. urticae eggs were laid either inside artificial or natural domatia in the laboratory experiment. Moreover, none of the artificial domatia favoured the pest mite total oviposition, i.e. inside + outside. A likely explanation is that spider mites do not need domatia to protect their eggs because they make their own webbing. However, whether this webbing also protects eggs against desiccation at low RH levels is not known.

In the laboratory experiment, the probability of $N$. californicus oviposition inside artificial domatia was best explained by a high capacity for heat retention of the materials, although it was not a perfect predictor. Among the five artificial domatia that were found to be as attractive as natural domatia in our study, wool, silk, viscose and polyamide 1 had this feature. Polyester 2 was the only artificial domatia as attractive as natural domatia that had a low heat retention capacity. This result suggests that other 
429 factors, other than the heat retention capacity of artificial domatia, may have been

430 involved in oviposition site selection. $N$. californicus is a natural enemy found in both

431 humid and arid climate zones (Castagnoli \& Simoni, 2003) and is known to thrive at

432 high temperatures (Castagnoli, M., \& Simoni, S., 1991). Therefore, an artificial

433 domatium characterized by a high heat retention capacity can be beneficial to $N$.

434 californicus by providing warmer temperatures and a buffer to temperature fluctuations.

435 A similar test with other predatory mite species may produce different results.

436 Furthermore, different life stages of the same mite species may possibly respond

437 differently to different climatic conditions.

$438 \quad$ The other tested physical properties of the artificial domatia were unable to

439 explain our data. Indeed, RH absorbency, domatia mimicking morphology (or

440 otherwise), fibre density, fibre diameter, and material thickness did not discriminate

441 favourable artificial domatia.

RH absorbency capacity of artificial domatia had no impact on oviposition

443 inside, which may be explained by the high level of RH maintained in the laboratory

444 experiment. In addition, other studies have reported contrasting results regarding the

445 microclimate benefits of domatia on mite populations (Ferreira et al., 2010; Grostal \&

446 O’Dowd, 1994; Norton et al., 2001; Rowles \& O’Dowd, 2009; Walter, 1996).

447

In the laboratory experiment, the morphology of artificial domatia had no effect

448

449

450

451

452

453

on the number of eggs laid inside by $N$. californicus. The predatory mite did not favour

a specific morphology type whether it was similar to or different from the natural

domatia. Our findings are not corroborated by Nishida, S., Naiki, A., \& Nishida, T.

(2005) who demonstrated that domatia may be more or less adapted depending on the

ecological contexts. For example, different mite species inhabit domatia with different opening sizes. 
In our study, fibre density did not correlate with the number of eggs laid inside

455

456

457

458

459

460

461

462

463

464

465

466

467

468

469

470

471

472

473

474

475

476

477

478

artificial domatia by the predatory mite. However, Roda et al. (2001) showed that $T$. pyri preferred to live and lay eggs in the highest density of available cotton fibres. In addition, an experiment on bean seedlings showed that a higher cotton fibre density was associated with a higher number of T. pyri (Loughner et al., 2010).

Similarly, in the laboratory experiment, thickness of artificial domatia had no impact on the number of eggs laid inside artificial domatia. However, this factor might play an important role in greenhouse or field conditions, particularly in conjunction with artificial domatia density. Indeed, phytoseiids are known to prefer micro-environmental conditions in the inner canopy leaves rather than in the outer ones (Allen \& Syvertsen, 1981). Moreover, Tachi and Osakabe (2012) reported that N. californicus actively avoided both solar UV and visible light radiation. Therefore, thicker and more dense materials are expected to provide better protection to all life stages of $N$. californicus. Most of the physical and morphological properties of the artificial domatia tested in the laboratory experiment could not explain our data. However, even if several studies have demonstrated the role of these factors on the development of Phytoseiidae populations, the results may be dependent on the mite species studied. The present study is the first to test the effect of artificial domatia on $N$. californicus oviposition.

In addition to the major physical and morphological factors tested in this study, other factors such as volatile components, fibre microstructure, UV absorbency (possibly linked to material thickness) may have an impact on $N$. californicus oviposition and interact with heat retention, the only significant factor identified in this study.

In the greenhouse experiment, the presence of artificial domatia strips on the rose plants had no effect on the total number of $N$. californicus individuals. Even wool, 
479

480

481

482

483

484

485

486

487

488

489

490

491

492

493

494

495

496

497

498

499

500

501

502

characterized by the favourable physical property identified in the laboratory experiment, i.e. a high capacity to retain heat, did not boost the predatory mite population. Four explanations are possible. First, in comparison to the stable laboratory conditions, the fluctuating climatic conditions in the greenhouse were probably constraining. Predatory mites probably preferred the climatic conditions at the boundary layer of the plants rather than the wool. Indeed, the boundary layer is a thin zone of air that surrounds each leaf. Its thickness influences how quickly gasses and energy are exchanged between the leaf and the surrounding air (Runkle, 2016). Boundary layers are known to improve biological control efficiency, in particular by providing more stable RH conditions (Boulard et al., 2004; Fatnassi et al., 2014). Second, Loughner et al. (2011) demonstrated that the way materials are applied to the plant strongly influences their effectiveness. Although Adar et al. (2014) successfully used a combination of uncoated $15 \mathrm{~cm}$ twines and pollen on the leaves of pepper plants for $A$. swirskii, Loughner et al. (2011) sifted finely-chopped acrylic fibres on impatiens leaves. The material strips are practical but may not be adequate as oviposition shelters. Third, the inability of the artificial domatia strips to adequately mimic the spatial distribution of leaf domatia on the rose plants. Situngu, S., \& Barker, N. (2017) showed that mites were more abundant and diverse on lower and internal parts of the canopy, characterized by old leaves bearing more domatia, for two tree species [Ocotea bullata (Lauraceae) and Gardenia thunbergia (Rubiaceae)]. This suggests that the distribution of microhabitats is a crucial factor for the population dynamics of predatory mites. Optimizing the spatial distribution and the application method for artificial domatia in cropping systems may improve the establishment of predatory mites. Lastly, providing pollen or another resource may also interact positively with the presence of artificial 
503 domatia and improve the predatory mite establishment, as recently evidenced by Pekas

504 and Wäckers (2017).

$505 \quad$ Neoseiulus californicus did not lay any eggs inside the organic wool. The lanolin 506 grease present in the organic wool is secreted by the sebaceous glands of wool-bearing 507 animals (López-Mesas, M., Carrillo, F., Guttiérrez, M. C., \& Crespio, M., 2007) and it 508 produces a specific odour (Lisovac \& Shooter, 2003) which may repel arthropods.

509 In contrast with the laboratory experiment, the presence of polyamide strips on 510 rose plants greatly promoted the population of $T$. urticae, although polyamide also 511 favoured $N$. californicus in the greenhouse experiment (Fig. 5a). Polyamide 1 hosted a 512 significant number of predatory mite eggs in the Petri dishes, which were characterised 513 by stable and saturated RH conditions. In contrast, this artificial domatium did not 514 perform as well under the fluctuating $\mathrm{RH}$ conditions of the greenhouse experiment. It 515 could be due to the low RH absorbency capacity of the material. 
517 The aim of this study was to identify artificial microhabitats to host N. californicus eggs

518 as effectively as natural domatia do. The results of the laboratory experiment supported

519 our hypotheses that artificial domatia, such as fabrics, could constitute artificial

520 oviposition sites for the predatory mite, but would not improve the reproduction of the

521 T. urticae phytophagous mite. Five of the twelve investigated artificial domatia were

522 particularly attractive for $N$. californicus oviposition. It was found that $N$. californicus

523 favoured artificial domatia with a high heat retention capacity for oviposition, such as

524 those composed of wool. However, testing the most efficient artificial domatia on whole

525 plants under greenhouse conditions produced different results. None of the tested

526 materials enhanced biocontrol by $N$. californicus and one (polyamide) even favoured the

527 T. urticae pest population.

528 Improving predatory mite habitat suitability is essential to sustainably improve

529 their establishment in a cropping system. Our findings highlighted the difficulty in

530 identifying selection criteria for artificial domatia that were likely to ensure a

531 sustainable establishment of the $N$. californicus predatory mite. They also underlined

532 the difficulty in finding a trade-off between an efficient, yet practical way for growers to

533 apply the artificial domatia in greenhouse conditions. This study further demonstrated

534 that artificial domatia should be specifically selected according to the life history and

535 behaviour of each predatory mite species.

536

\section{Acknowledgements}

538 We are grateful to Besma Khelil and Lionel Salvy for their assistance during the experiment.

539 The study was conducted with partial funding from the European Union Seventh Framework 
Program (FP7/2007-2013) under grant agreement n 265865 (project PURE), from the

European INTERREG ALCOTRA Programme (2007-2013) under the grant agreements $n^{\circ} 178$ (FIORIBIO 2 project) and n 264 (ECOLEGO project), and from DEPHY EXPE ECOPHYTO (OTELHO Project). This research has been integrated in the framework program of UMT FioriMed since 2015. The manuscript was proofread by a professional English Language Editing service.

\section{Conflicts of Interest}

The authors declare that there are no conflicts of interest.

\section{References}

Hirotugu Akaike. (1973). Information theory and an extension of the maximum likelihood principle. Proceedings Second International Symposium on Information Theory, pp. 267-281

Allen J, Syvertsen JP (1981). The world of the citrus rust mite: a microclimate prediction problem. In Kommedahl, T. (Eds.). Proceedings of symposia: IX International Congress of Plant Protection,Washington, 1, (pp. 138-140). Adar, E., Inbar, M., Gal, S., Gan-Mor, S., \& Palevsky, E. (2014). Pollen on-twine for food provisioning and oviposition of predatory mites in protected crops. BioControl, 59, 307-317.

Agrawal, A. A., Karban, R., \& Colfer, R.G. (2000). How leaf domatia and induced plant resistance affect herbivores, natural enemies and plant performance. Oikos, 89, 70-80.

Boulard, T., Fatnassi, H., Roy, J.C., Lagier, J., Fargues, J., Smits, N., ..., \& Jeannequin, B. (2004). Effect of greenhouse ventilation on humidity of inside air and in leaf boundary-layer. Agricultural and Forest Meteorology, 125, 225-239. Castagnoli, M., \& Simoni, S. (2003). Neoseiulus californicus (McGregor) (Acari, Phytoseiidae): survey of biological and behavioural traits of a versatile predator. Redia, 86, 1-12

Castagnoli, M.; Simoni, S. \& Nachman, Gö. (2001).Short-term changes in consumption and oviposition rates of Neoseiulus californicus strains (Acari: Phytoseiidae) after a diet shift. Experimental \& Applied Acarology, 25, 969-983. 
Castagnoli, M., \& Simoni, S. (1991). Influence of temperature on population increase of amblyseius californicus McGregor acari phytoseiidae. Redia, 74, 621-640

Easterbrook, M. A., Fitzgerald, J. D., \& Solomon, M. G. (2001). Biological control of strawberry tarsonemid mite Phytonemus pallidus and two-spotted spider mite Tetranychus urticae on strawberry in the UK using species of Neoseiulus (Amblyseius) (Acari: hytoseiidae). Experimental \& Applied Acarology, 25, 2536.

English-Loeb, G.; Andrew, P. N. \& Walker, M. A. (2002). Behavioral and population consequences od acarodomatia in grapes on phytoseiid mites (Mesostigmata) and implications for plant breeding. Entomologia Experimentalis Et Applicata, 104, 307-319.

Faraji, F., Janssen, A., \& Sabelis, M. W. (2002). Oviposition patterns in a predatory mite reduce the risk of egg predation caused by prey. Ecological Entomology, 27, 660-664.

Fatnassi, H., Boulard, T., Poncet, C., Bartzanas, T., Katsoulas, N., Kacira, M. (2014). CFD modeling of microclimate in the leaf boundary layer. Ecological Niche of Pests. Acta Hort (ISHS), 1037,1027-1034.

Ferreira, J. A. M., Pallini, A., Oliveira, C. L., Sabelis, M. W., \& Janssen, A. (2010). Leaf domatia do not affect population dynamics of the predatory mite Iphiseiodes zuluagai. Journal of Basic and Applied Ecology, 11, 144-152.

Frank, S. D. (2010). Biological control of arthropod pests using banker plant systems: past progress and future directions. Biological Control, 52(1): 8-16. García-Marí, F., \& González-Zamora, J. E. (1999). Biological control of Tetranychus urticae (Acari: Tetranychidae) with naturally occurring predators in strawberry plantings in Valencia, Spain. Experimental \& Applied Acarology, 23, 487-495 Gerson, U., \& Weintraub, P. (2012). Mites (Acari) as a factor in greenhouse management. Annual Review of Entomology, 57,229-47.

Grostal, P., \& O’Dowd, D. J. (1994). Plants, mites and mutualism - leaf domatia and the abundance and reproduction of mites on Viburnum tinus (Caprifoliaceae). Oecologia, 97, 308-315.

Huang, N., Enkegaard, A., Osborne, L. S., Ramakers, P. M. J., Messelink, G.J., Pijnakker, J., \& Murphy, G. (2011). The banker plant method in biological control. Critical Reviews in Plant Sciences, 30, 259-278. 
Ishimaru S. (2016). Heat-Controllable Man-Made Fibers. In: The Society of Fiber Science and Techno J. (Ed.), High-Performance and Specialty Fibers (pp. 261269). Tokyo: Springer.

Karban, R., English-Loeb, G., Walker, M.A., \& Thaler, J. (1995). Abundance of Phytoseiid mites on Vitis species: effects of leaf hairs, domatia, prey abundance and plant phylogeny. Experimental and Applied Acarology, 19, 189-197. Kawashima, M., Adachi, I., \& Toyama, M. (2006). Artificial microstructure encouraging the colonization of the predacious mite, Neoseiulus californicus (McGregor) (Acari: Phytoseiidae). Applied Entomology and Zoology, 41, 633-639. Kawashima, M., \& Jung, C. (2011). Effects of sheltered ground habitats on the overwintering potential of the predacious mite Neoseiulus californicus (Acari: Phytoseiidae) in apple orchards on mainland Korea. Experimental and Applied Acarology, 55, 375-88.

(2002). Plants and leaf characteristics influencing the predaceous mite Kampimodromus aberrans (Acari: Phytoseiidae) in habitats surrounding vineyards. Environmental Entomology, 31, 648-660.

Kumar, V., Wekesa, V. W.,Avery, P. B.,Powell, C. A.; McKenzie, C. L., \& Osborne, L. S. (2014). Effect of pollens of various ornamental pepper cultivars on the development and reproduction of Amblyseius swirskii (Acari: Phytoseiidae). Florida Entomologist, 97, 367-373.

Lisovac, A., \& Shooter, D. (2003). Volatiles from sheep wool and the modification of wool odour. Small Ruminant Research, 49, 115-124.

López-Mesas, M., Carrillo, F., Guttiérrez, M. C., \& Crespio, M. (2007). Alternative methods for the wool wax extraction from wool scouring wastes. Grasas y aceites, 58, 402-407.

Loughner, R., Wentworth, K., Loeb, G., \& Nyrop, J. (2010). Leaf trichomes influence predatory mite densities through dispersal behavior. Entomologia Experimentalis Et Applicata, 134, 78-88.

Loughner, R., Nyrop, J., Wentworth, K., \& Sanderson, J. 2011. Towards enhancing biocontrol of thrips: effects of supplemental pollen and fibres on foliar abundance of Amblyseius swirskii. IOBC/WPRS Bulletin, 68, 105-109. Mac Murtry, J. \& Croft, B. (1997). Life-styles of Phytoseiid mites and their roles in biological control. Annual Review of Entomology, 42, 291-321.

Messelink, G. J., Bennison, J., Alomar, O., Ingegno, B.L., Tavella, L., Shipp, L., ..., \& Wäckers, F.L. (2014). Approaches to conserving natural enemy populations in greenhouse crops: current methods and future prospects. Biological Control, 59, 377-393. 
Nishida, S., Naiki, A., \& Nishida, T. (2005). Morphological variation in leaf domatia enables coexistence of antagonistic mites in Cinnamomum camphora. Canadian Journal of Botany, 83, 93-101.

Norton, A. P., English-Loeb, G., \& Belden, E. (2001). Host plant manipulation of natural enemies: leaf domatia protect beneficial mites from insect predators. Oecologia, 126, 535-542.

Nundloll, S.; Mailleret, L. \& Grognard, F. (2008).The effect of partial crop harvest on biological pest control. The Rocky Mountain Journal of Mathematics, 38, 16331661

O'Dowd D. J., \& Willson, M. F. (1989). Leaf domatia and mites on Australasian plants: ecological and evolutionary implications. Biological Journal of the Linnean Society, 37, 191-236.

Parolin, P., Bresch, C., Van Oudenhove, L., Errard, \& A., Poncet, C. (2015). Distribution of pest and predatory mites on plants with differing availability of acarodomatia. International Journal of Agricultural Policy and Research, 3,267-278.

Parolin, P, Bresch, C., Ruiz, G., Desneux, N., \& Poncet, C. (2013). Testing banker plants for biological control of mites on roses. Phytoparasitica, 41,249-262. Pekas, A. \& Wäckers, F. L. (2017). Multiple resource supplements synergistically enhance predatory mite populations. Oecologia, 184, 479-484.

Pemberton, R., \& Turner, C. E. (1989). Occurrence of predatory and fungivorous mites in leaf domatia. American Journal of Botany, 76, 105-112.

R Core Team (2014) A language and environment for statistical computing. R Foundation for Statistical Computing, Vienna, Austria. URL http://www.Rproject.org/

Roda, A., Nyrop, J., Dicke, M., \& English-Loeb,G. (2000).Trichomes and spider-mite webbing protect predatory mite eggs from intraguild predation. Oecologia, 125, 428-435.

Roda, A., Nyrop, J., English-Loeb, G., \& Dicke, M. (2001). Leaf pubescence and twospotted spider mite webbing influence phytoseiid behavior and population density. Oecologia, 129, 551-560.

Rozario, S.A, (1994). Domatia and mites: effects of leaf morphology on beneficial mites in semi-natural and managed systems (Doctoral dissertation). Retrieved from https://catalogue.nla.gov.au/Record/2275037. Monash University. Rowles, A. D., \& O'Dowd, D. J. (2009). Leaf domatia and protection of a predatory mite Typhlodromus dereenae Schicha (Acari: Phytoseiidae) from drying humidity. Australian Journal of Entomology, 48, 276-281. 
682 Runkle, E. (2016). The boundary layer and its importance. GPNMAG.COM. Retrieved from http://flor.hrt.msu.edu/assets/Uploads/Boundary-layer.pdf.

Situngu, S., \& Barker, N.(2017). Position, position, position: mites occupying leaf domatia are not uniformly distributed in the tree canopy. South African Journal of Botany, 108, 23-28.

Tachi, F., \& Osakabe, M. (2012). Vulnerability and behavioral response to ultraviolet radiation in the components of a foliar mite prey-predator system. Naturwissenschaften, 99, 1031-1038.

Walter D. E. \& O'Dowd J.R. (1992). Leaves with domatia have more mites. Ecology, 73,1514-1518.

Walter, D. E. (1996). Living on leaves: mites, tomenta, and leaf domatia. Annual Review Of Entomology, 41, 101-114.

Zhao, W., Zheng, W., Zhang, B., Yu, G., Hu, S., Xu, X. \& Zhanga, H. (2014). Effect of different ground cover management on spider mites (Acari: Tetranychidae) and their phytoseiid (Acari: Phytoseiidae) enemies in citrus orchards. Biocontrol Science and Technology, 24, 705-709. 